\title{
The pathogenesis of duodenal gastric metaplasia: the role of local goblet cell transformation
}

\author{
R Shaoul, P Marcon, Y Okada, E Cutz, G Forstner
}

\begin{abstract}
Background and aims-Gastric metaplasia is frequently seen in biopsies of the duodenal cap, particularly when inflamed or ulcerated. In its initial manifestation small patches of gastric foveolar cells appear near the tip of a villus. These cells contain periodic acid-Schiff (PAS) positive neutral mucins in contrast with the alcian blue (AB) positive acidic mucins within duodenal goblet cells. Previous investigations have suggested that these PAS positive cells originate either in Brunner's gland ducts or at the base of duodenal crypts and migrate in distinct streams to the upper villus. To investigate the origin of gastric metaplasia in superficial patches, we used the PAS/AB stain to distinguish between neutral and acidic mucins and in addition specific antibodies to immunolocalise foveolar cell mucin MUC5AC, the foveolar cell secretory product, gastric trefoil factor (TFF1), the mature goblet cell mucin MUC2, and MUC2 core antigen.
\end{abstract}

Results-Cells in focal patches of gastric metaplasia contained secretory granules of both gastric and goblet cell phenotypes. MUC5AC and TFF1 were present as expected in gastric foveolar cells but in addition, MUC2 core antigen, normally present only in the Golgi of intestinal goblet cells, was expressed in secretory granules. Goblet cells in the vicinity of metaplastic patches also expressed both gastric and intestinal antigens. MUC5AC/ MUC2 containing goblet cells were most common near the villus tip but were also seen at the base of crypts. Where crypts and Brunner's gland ducts merged they were always seen on the crypt side of the junction. Goblet cells were the only cells to express gastric antigens in these areas. In advanced metaplastic lesions, dual phenotype goblet cells were less evident and fewer cells expressed intestinal mucin antigens.

Conclusions-We suggest that goblet cells that express both intestinal and gastric antigens may represent local precursors of gastric metaplasia undergoing a transition to foveolar-like cells of mixed phenotype at the site of early metaplastic patches. As metaplasia becomes more widespread, a more pure gastric phenotype emerges. This progression is likely to be controlled by local inflammatory signals.

(Gut 2000;46:632-638)

Keywords: gastric metaplasia; goblet cells; mucin
Gastric metaplasia is characterised by the appearance of clusters of epithelial cells of gastric phenotype in non-gastric epithelium and may occur anywhere in the intestine and colon. In the duodenum it is found in a small percentage of otherwise normal biopsies ${ }^{1}$ but is much more frequently seen in association with inflammation. ${ }^{2-4}$ During the past decade the frequent association of duodenal gastric metaplasia with Helicobacter pylori gastritis has been recognised $^{5-9}$ and its potential importance highlighted as a possible starting site for peptic ulceration. ${ }^{5}$ Gastric metaplasia has also been reported in Crohn's disease of the duodenum $^{10-12}$ and non-specific chronic duodenitis. $^{23} 612$

In the small intestine the earliest manifestation usually occurs as a small island of transformed epithelium on the tip or side of a villous. ${ }^{513}$ Metaplastic cells resemble the superficial gastric mucous secreting cell of the antral and gastric pits or foveoli. ${ }^{914-16}$ These cells contain a periodic acid-Schiff (PAS) neutral mucin which contrasts with the alcian blue positive acidic mucins elaborated by intestinal goblet cells. The superficial origin of these cells suggests that they might originate by local transformation of neighbouring cells. Liu and Wright, ${ }^{16}$ however, described tight cohorts or migration streams of PAS positive cells that appeared to be derived from Brunner's gland duct epithelium or from basal buds beginning in the crypts of Lieberkühn. Evidence from the same laboratory, indicating that gastric trefoil factor (TFF1, formerly pS2) $\operatorname{protein}^{17}{ }^{18}$ and mRNA $^{18}$ were expressed in both gastric metaplasia and Brunner's duct cells also suggested that metaplastic cells might originate in Brunner's gland ducts. Rio and colleagues ${ }^{19}$ found no evidence, however, that Brunner's gland elements expressed immunoreactive TFF1 protein or mRNA. In any case Brunner's glands are not essential as gastric metaplasia clearly develops in areas of the intestine that lack them. In these areas Wright and colleagues $^{12} 2021$ have provided evidence that gastric metaplasia originates in a novel PAS positive cell line, the so called ulcer associated cell lineage (UACL) that buds from the base of a regenerating crypt and migrates as an elongating tube through the lamina propria until it reaches and fuses with the surface epithelium.

In the present study we have examined the origin of superficial gastric metaplasia in the duodenum using histochemistry and immunohistochemistry to detect gastric and intestinal

Abbreviations used in this paper: PAS, periodic acid-Schiff; $\mathrm{AB}$, alcian blue; $\mathrm{TFF} 1$, gastric trefoil factor; UACL, ulcer associated cell lineage. 
mucins as well as TFF1, paying particular attention to focal lesions and junctional areas between crypts and Brunner's glands. We present evidence that suggests that transformation of local intestinal goblet cells to a gastric phenotype may be the initial event leading to the appearance of metaplasia.

\section{Methods}

We studied biopsies from 18 patients with duodenitis (non-specific $(n=3)$, associated with Helicobacter pylori $(\mathrm{n}=7)$, or Crohn's disease $(n=8))$ and 10 age matched normal controls (ages 8-18 years), obtained from our histology archives. Biopsies were fixed in $10 \%$ formalin, embedded in paraffin, and stained with haematoxylin and eosin and PAS/alcian blue (PAS/ $\mathrm{AB})$. Antigen retrieval was achieved by microwaving sections on slides ${ }^{22}$ in $0.01 \mathrm{~mol} / 1$ sodium citrate, $\mathrm{pH}$ 6.0, standardised for the microwave in our pathology laboratory. ${ }^{23}$ Immunostaining utilised antibodies raised against MUC2 core (Novocastra Lab. Ltd, Newcastle upon Tyne, UK), glycosylated MUC2, ${ }^{24}$ MUC5AC, ${ }^{25}$ and TFF1, ${ }^{26}$ and was performed using an indirect immunoperoxidase method. ${ }^{27}$ In brief, endogenous peroxidase was blocked with $3 \% \quad \mathrm{H}_{2} \mathrm{O}_{2}$ for 15 minutes. The sections were blocked with $5 \%$ normal goat serum (Vector Labs., Burlingame, California, USA) and then incubated with the primary antibody for one hour at room temperature. In control sections, incubation with the primary antibody was omitted. The slides were then washed three times with PBSBSA, incubated for 45 minutes at room temperature with biotinylated goat antirabbit IgG (Molecular Probes, Eugene, Oregon, USA) for glycosylated MUC2, or donkey antimouse IgG (Jackson ImmunoResearch Labs., West Grove, Pennsylvania, USA) for MUC2 core, MUC5AC, and TFF1, washed three times as above, and then incubated with avidin peroxidase (Molecular Probes, Eugene, Oregon, USA) for 45 minutes at room temperature, followed by three final washes in Tris buffered saline. Bound antibody complex was visualised by reaction in 3,3'-diaminobenzidine (DAB) substrate (Research Genetics, Huntsville, Alabama, USA) and counterstained with Harris haematoxylin.

For electron microscopy, blocks fixed in paraffin were deparaffinised in chloroform overnight and rehydrated by incubation in phosphate buffer containing decreasing concentrations of alcohol solutions to phosphate buffer alone. After a minimum of two hours in phosphate buffer, biopsies were fixed in universal fixative (equal parts of $4 \%$ formaldehyde and $1 \%$ glutaraldehyde) and post fixed in $2 \%$ osmium tetroxide. Dehydration was carried out in graded acetone and embedding in epon. Thick sections $(1 \mu \mathrm{m})$ were stained with toluidine blue and ultrathin sections were stained with uranyl acetate and lead citrate. Electron microscopic examination was performed under a Phillips 201 (NV PHILIPS, Gloeilampenfarbrieken, Eindhoven, the Netherlands) transmission electron microscope.

\section{Results}

Antibodies to the gastric mucin MUC5AC and TFF1 were used to identify cells with a gastric phenotype. MUC5AC was localised to the mucous secreting cells of the upper segment and surface of the glands of the gastric antrum (fig 1A) and was not ordinarily present in the mucous secreting goblet cells of the duodenum (fig 1B). TFF1 was confined to cells that contained MUC5AC in the normal antrum but was present in more superficial cells (fig 1C). Figure 1D shows a goblet cell on a normal duodenal villous with granules that are weakly stained for TFF1. This cell was MUC5AC negative. In general very few goblet cells in the normal duodenum were TFF1 positive.

When gastric metaplasia was localised to segmental areas of duodenal biopsies it was found in superficial areas of the villus. Cells in these areas were strongly MUC5AC positive (fig 1E). TFF1 was expressed in MUC5AC containing cells in metaplastic areas (fig $1 \mathrm{~F}$, arrows) but, as in the normal antrum, was limited to fewer and more superficial metaplastic cells. Areas of gastric metaplasia contained cells with apical mucous granules that stained an intense red with the PAS/AB stain (fig 1G, arrowhead) in contrast with the bluish purple $\mathrm{AB}$ positive colour of neighbouring duodenal goblet cells. In fig 1G, PAS positive staining is also present in metaplastic cells in a tangentially sectioned upper crypt zone (arrow). A serial section of the same biopsy (fig $1 \mathrm{H}$ ) stained with MUC5AC antibody shows that these PAS positive cells express MUC5AC (arrows). In addition, fig $1 \mathrm{H}$ shows that many of the $\mathrm{AB}$ positive goblet cells in the surrounding area are positively stained for MUC5AC. Some of these goblet cells also expressed TFF1.

In spite of the positive staining for MUC5AC and TFF1, goblet cells near metaplastic zones were alcian blue positive, suggesting that they must also contain significant amounts of intestinal mucin. To confirm this we studied the distribution of MUC2, the principal intestinal mucin, using an antibody that reacts with mature mucin. Figure 2 compares staining for MUC2 and MUC5AC in antral and duodenal biopsies. There was no evidence of cross reactivity between these antibodies in the antrum. Anti-MUC2 antibody did not react with antral mucous secreting cells (fig 2A) that, as shown in a serial biopsy section (fig 2B), contain MUC5AC. Figure 2C and 2D are serial sections from a duodenal biopsy containing an area of gastric metaplasia, stained for MUC2 (fig 2C) and MUC5AC (fig 2D). All of the goblet cells stained positively for MUC2 and many also contained MUC5AC. Thus a cohort of goblet cells is seen in the presence of gastric metaplasia that expresses both gastric and intestinal mucins.

In some areas metaplastic cells were also weakly stained by the antibody to the mature MUC2 suggesting that some cells might express both intestinal and gastric markers. Electron microscopy of areas of focal metaplasia also suggests that there is considerable heterogeneity among the cells in these areas 

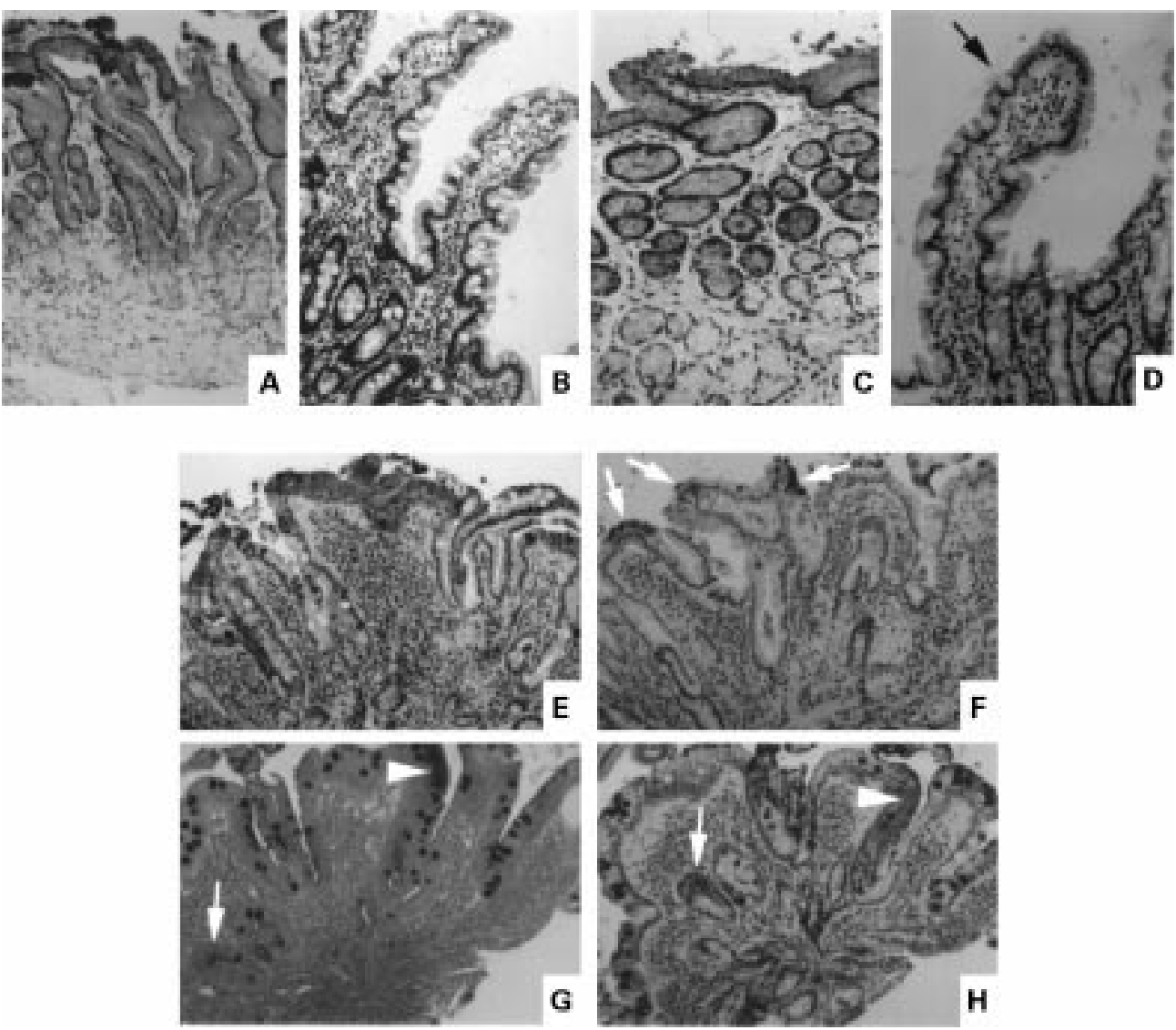

Figure 1 Immunohistochemical localisation of the gastric mucin MUC5AC and gastric trefoil factor (TFF1) in normal antrum and duodenum $(A-D)$, and duodenum containing focal gastric metaplasia $(E, F$, and $H)$. (A) MUC5AC, normal antrum; (B) MUC5AC, normal duodenum; (C) TFF1 in the same area of the antral biopsy shown in $(A) ;(D)$ TFF1, normal duodenum, arrow marks a weakly stained goblet cell; $(E, F)$ serial sections of duodenum containing gastric metaplasia ((E) MUC5AC, $(F)$ TFF1), arrows show positively stained areas; $(G, H)$ serial sections stained by PAS/AB $(G)$ and for MUC5AC $(H)$, arrows point to sites of PAS staining; in $(G)$, all goblet cells were AB positive.
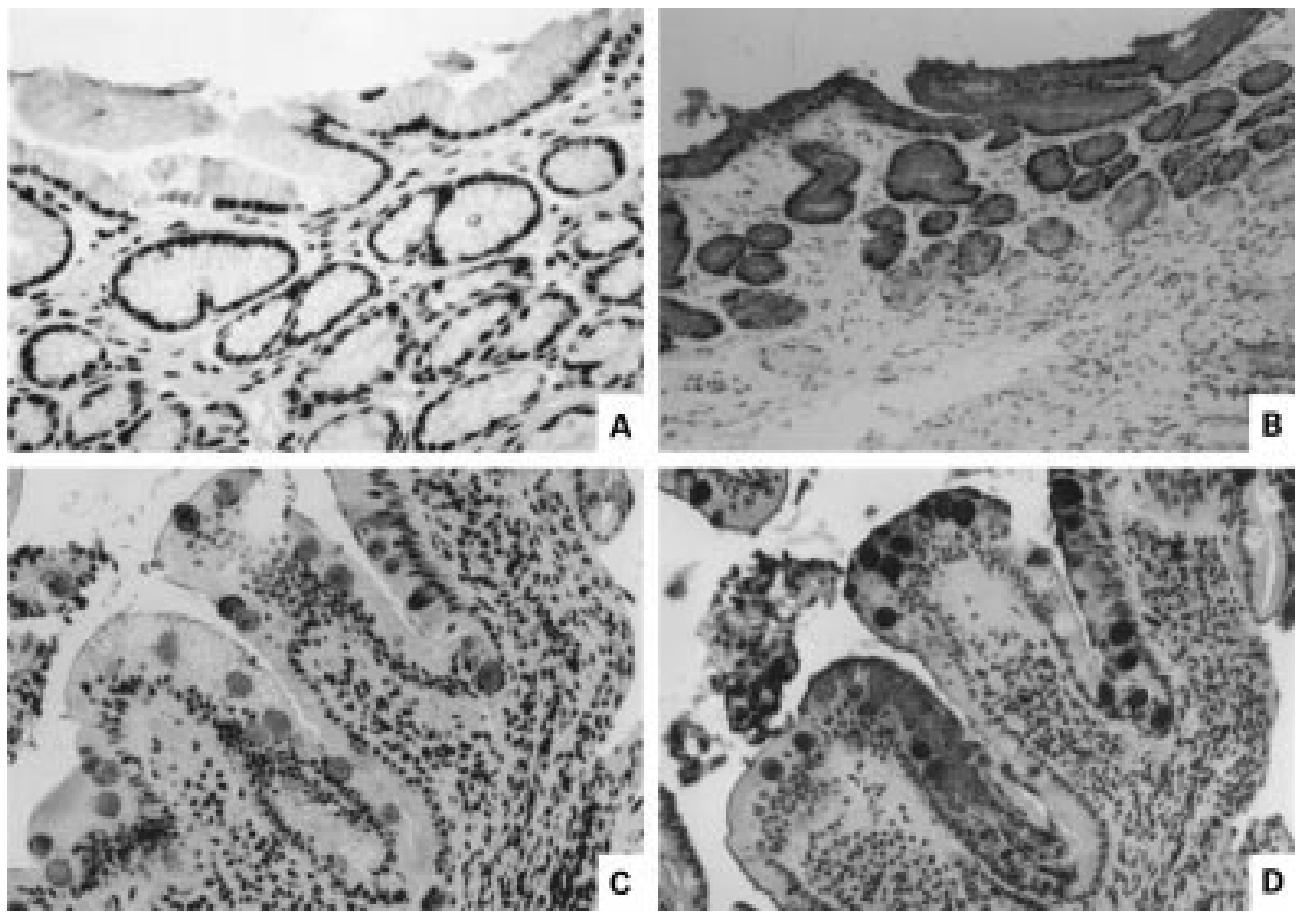

Figure 2 Distribution of intestinal mucin MUC2 and gastric mucin MUC5AC in serial sections of antrum and duodenum. (A) MUC2, normal antrum; (B) MUC5AC, normal antrum; (C, D) duodenum containing focal gastric metaplasia ((C) MUC2; (D) MUC5AC). 

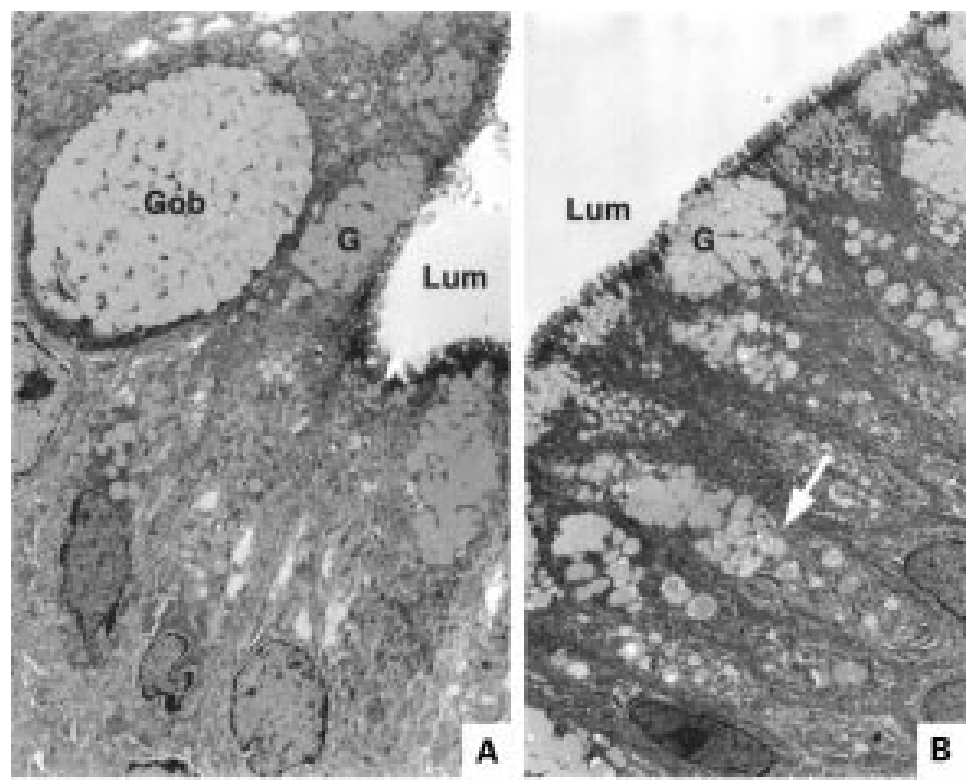

Figure 3 Electron micrograph of two areas within a patch of focal metaplasia. In each, Lum=lumenal surface. (A) Gob, a cell containing mucous secretory granules typical of intestinal goblet cells; $G$, mucus secretory granules typical of gastric foveolar cells. (B) Arrow shows single cell containing granules typical of both gastric and intestinal phenotypes; $G$, mucus granules with gastric phenotype.

with features of both gastric and intestinal mucous secreting cells. Figure $3 \mathrm{~A}$ shows a number of mucous secreting cells in a metaplastic focus with a characteristic gastric appearance consisting of closely packed, dense, uniform granules, contrasted with a single cell resembling a goblet cell which contains less dense granules of heterogeneous size, with poorly demarcated granular membranes, some of which appear to have fused. In a neighbouring area (fig 3B) two cells are seen that contain both light and dense granules with features typical of both foveolar and goblet cells. In control samples of normal gastric antral mucosa prepared in an identical manner, mucous producing cells showed uniform granules without mixed phenotype (not shown).

The likelihood that gastric metaplastic cells are a mixed phenotype sharing both gastric and intestinal mucin products was strengthened by immunostaining for MUC2 core antigen (fig $4)$. This antigen is normally demonstrable in the base of intestinal goblet cells in the region of the Golgi apparatus (fig 4A) and does not react with mature mucin in the goblet cell mass. It also does not react with mucin in gastric foveolar cells (fig 4B). As demonstrated in fig 4C, however, MUC2 core antigen was expressed in the granules of metaplastic cells, along with MUC5AC (fig 4D). Thus although metaplastic cells do not elaborate large amounts of mature MUC2 (fig 2C), they produce and transport impressive quantities of the immature MUC2 mucin core into secretory granules.

In the majority of our biopsies we were impressed with the fact that goblet cells with mixed phenotype were more common in the neighbourhood of the metaplastic patches. Similar observations have been made previously with respect to goblet cells that expressed TFF $1 .{ }^{18} 2829$ The sections shown in fig 5 were chosen as particularly clear examples of this clustering. Panels A, B, and C in fig 5 are serial sections showing the distribution of cells containing MUC5AC (fig 5A), TFF1 (fig 5B), and mature MUC2 (fig 5C). An area of focal gastric metaplasia shows intense staining for MUC5AC (fig 5A, black arrow). TFF1 positive
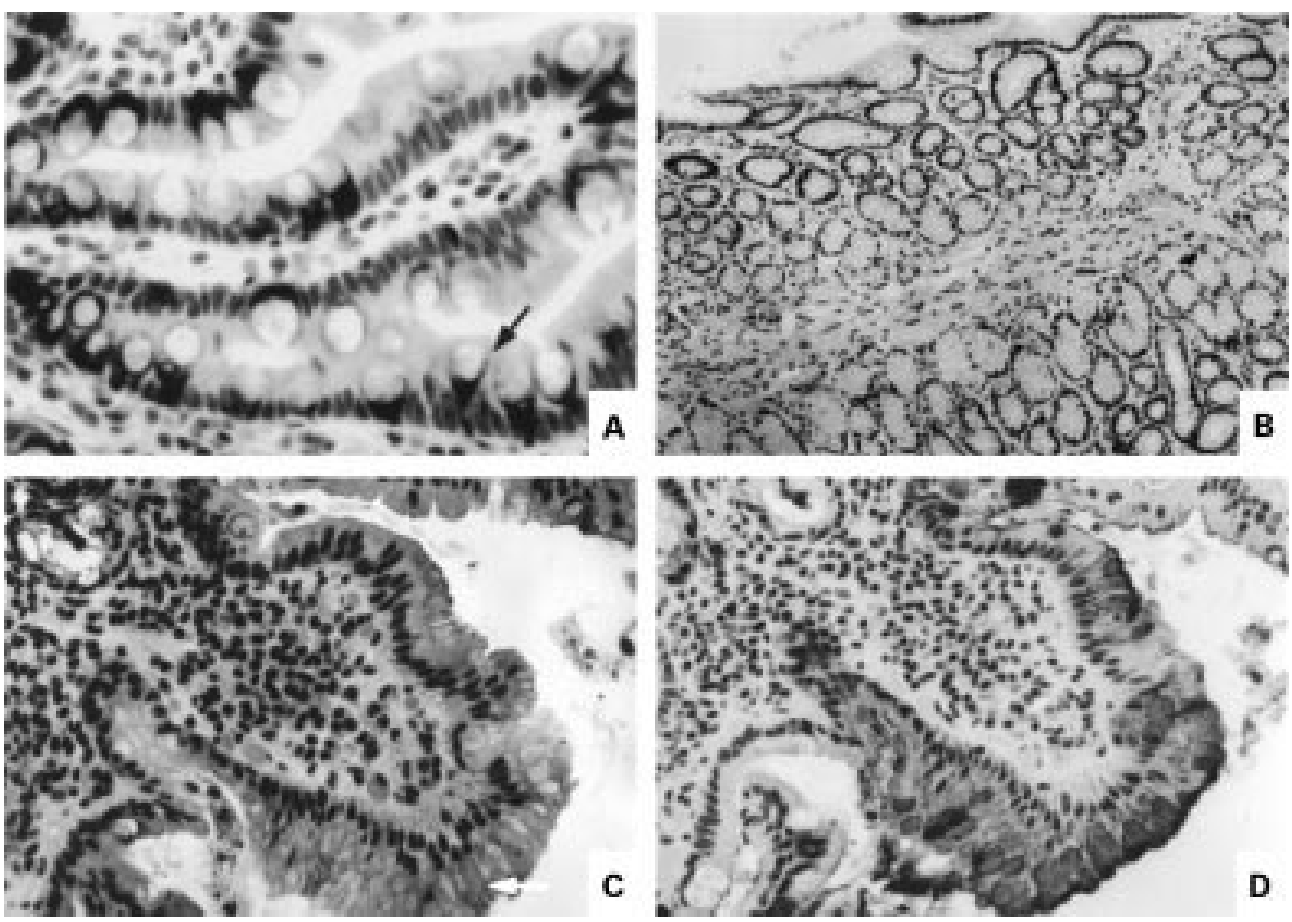

Figure 4 Immunolocalisation of MUC2 core antigen. (A) Normal duodenum showing staining for core antigen in the supranuclear Golgi region at the base of the goblet cell storage granule mass (arrow); (B) absence of core antigen staining in normal antrum; (C) MUC2 core antigen in the secretory granules of cells in a focal area of duodenal gastric metaplasia (arrow); (D) MUC5AC staining of area shown in (C). 

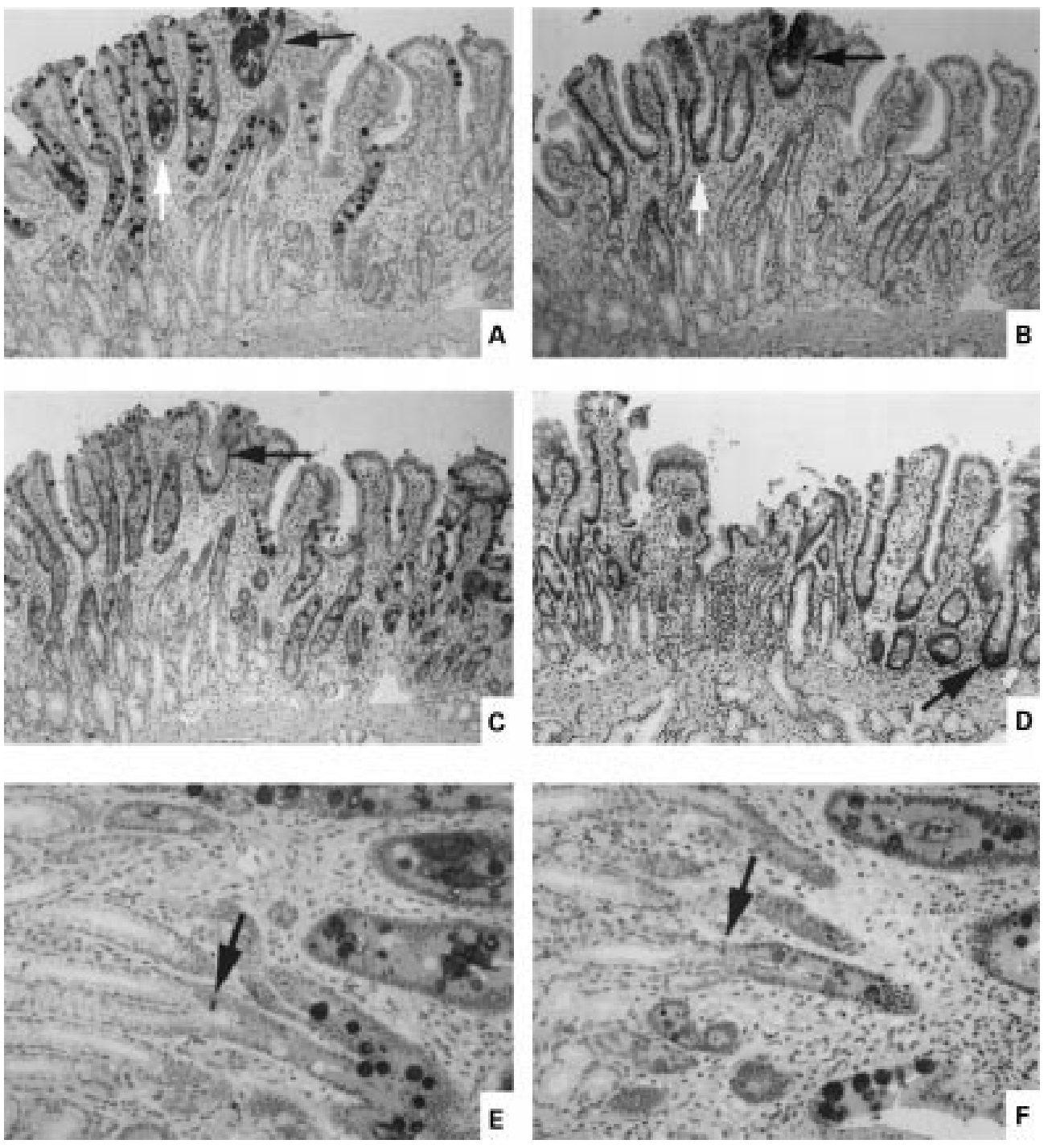

Figure 5 Expression of gastric and intestinal markers in cells near a patch of focal duodenal gastric metaplasia. Panels $A-D$ are serial sections of well oriented mucosa showing entire crypt-villus unit plus junctional zone between crypts and Brunner's gland ducts. (A) MUC5AC; (B) gastric trefoil factor (TFF1); (C) MUC2; (D) human defensin 5 (HD5). The arrows in $(A),(B)$, and $(C)$ show an area of metaplasia. In (D), the arrow shows a positively stained Paneth's cell at the base of a crypt. (E, F) Serial sections at higher magnification of the junctional zone between Brunner's gland ducts and crypts ((E) MUC5AC; (F) MUC 2). The arrows show a stained cell of indeterminate phenotype at the junction of crypt and duct.

cells are present in the more superficial portion of this metaplastic area (fig 4B, black arrow). In the metaplastic area marked by the white arrow, TFF1 was absent. In agreement with the findings of Rio and colleagues, ${ }^{19}$ there was no evidence of TFF1 in Brunner's gland or duct. The area surrounding the patch of gastric metaplasia is notable for the number of MUC5AC containing goblet cells in the vicinity extending well down into the duodenal crypt (fig 5A). This area is strikingly related to junctional areas of Brunner's gland ducts with crypt bases. In contrast, MUC2 was present in all goblet cells, within and without the MUC5AC positive zone (fig 5C). Figure 5D identifies Paneth's cells at the crypt base with the human defensin 5 (HD5) marker. Paneth's cells were conspicuously absent from Brunner's gland duct-crypt junctions. Figure $5 \mathrm{E}$ and $\mathrm{F}$ show the crypt-duct junctional zone at higher magnification. MUC5AC containing goblet cells are evident above the junctional zone and one cell of indeterminate nature containing MUC5AC is evident at the junction (fig $5 \mathrm{E}$, arrow). This cell was also MUC2 positive (fig $5 \mathrm{~F}$ ), indicating that it likely represented an immature goblet cell. We never observed MUC5AC positive cells in Brunner's gland ducts nor did we see non-goblet MUC5AC positive cells that could represent the migrating epithelial precursor described by Liu and Wright. ${ }^{16}$ The number of goblet cells containing gastric mucin was generally highest in the superficial mucosa but fig $5 \mathrm{E}$ demonstrates that the MUC5AC phenotype can be acquired in the initial cells of the goblet cell lineage. In more severe examples of gastric metaplasia (not shown) involving the total mucosa goblet cells of dual phenotype were not seen and fewer cells in metaplastic areas expressed MUC2 antigen. Intermediate cells expressing both intestinal and gastric markers are therefore a feature of focal gastric metaplasia. 


\section{Discussion}

Our observations suggest that gastric metaplasia develops by transformation from a preexisting intestinal goblet cell lineage, initially forming cells that superficially resemble, but are not fully differentiated, gastric mucous secreting foveolar cells. Several lines of evidence support this conclusion. (1) Metaplastic cells in focal patches, unlike gastric foveolar cells, have secretory granules that are heterogeneous in appearance with features that resemble those of intestinal and gastric cells. (2) These granules contain intestinal and gastric mucins. (3) Much of the intestinal mucin in the granules of metaplastic cells reacts with an antibody to core $\mathrm{MUC2}$, an immature form of MUC2 that is usually confined to the Golgi zone of goblet cells. MUC2 core antigen is not present in gastric mucous secreting cells. (4) Focal metaplastic patches are surrounded by goblet cells that synthesise both intestinal and gastric mucins. (5) A small number of goblet cells close to metaplastic foci also express TFF1, a second marker of metaplastic cells. (6) As distance from the metaplastic patch increases, the proportion of goblet cells with a mixed phenotype diminishes. (7) The largest concentration of goblet cells with dual phenotype is seen in early, focal metaplasia and diminishes as metaplasia becomes generalised. (8) Candidate precursor cells exhibiting gastric markers, other than goblet cells, were not identified. Thus the earliest and smallest metaplastic lesions are associated with dual phenotype goblet cells which appear to arise from intestinal goblet cells during their upward migration. As these cells reach the villous tip, areas of metaplasia emerge that contain cells that lose their goblet cell features but retain evidence of dual phenotype. Often one or two goblet cells with mixed phenotype can be distinguished within early metaplastic patches. The dual phenotype goblet cells are the most likely precursors of the metaplastic cells not only because they accumulate in the vicinity but because they are the only cells that are programmed to express the mucins and TFF1 antigens that characterise gastric cells. Interestingly, the zone of metaplastic cells that contains $T F F 1$, a relatively specific gastric antigen, is smaller and more superficial than the zone stained by antiMUC5AC, suggesting that even within the metaplastic patches there is a continuing transformation toward a more gastric phenotype. In focal lesions these cells still packaged MUC2 core mucin, however, and therefore retained an intestinal character that was only lost in advanced gastric metaplastic lesions that totally replaced intestinal epithelium.

The concept of local transformation of existing cells is attractive for its economy, suggesting that local inflammatory mediators may play a major role in influencing epithelial phenotype. It does not require preprogramming at the stem cell level, although this is possible, and it would account very well for the appearance of superficial islands of metaplasia on villous tips far from the crypt base. Transformation of this nature is not without precedent in mucosal epithelium and is in fact part of the normal evolution of zymogen granule cells from mucous neck cells in gastric glands. ${ }^{30}$ Transitional forms between serous and mucous cells, and clara and mucous cells also appear in respiratory epithelium when exposed to irritants ${ }^{31}$ and are followed by mucous cell hyperplasia.

In contrast, alternative theories ${ }^{16}{ }^{18}$ advanced to explain duodenal gastric metaplasia require the emergence of a distinctive gastric foveolar precursor cell at the base of the crypt or in the Brunner's gland duct, followed by a long migratory route to the superficial patch of gastric metaplasia near the villous tip. Candidate precursor cells with PAS positive apical granules were identified in transverse sections of mucosa by Liu and Wright. ${ }^{16}$ We were unable to show that candidate cells of this nature contained either MUC5AC or TFF1. It is still possible, however, that precursor cells of this nature may not express gastric foveolar antigens until they arrive in a superficial location. This is apparently the case with cells of the UACL that bud from crypts and move toward the mucosal surface in ductules to form surface patches of gastric metaplasia. UACL cells do not express TFF1 until they reach a superficial location. ${ }^{32}$ Thus we cannot eliminate the possibility that a unique migratory cell lineage could form superficial patches of gastric metaplasia, but the case will depend ultimately on identifying the putative precursors with greater precision. It is also possible that cross sectional sections with reconstruction, as performed by Liu and Wright, ${ }^{16}$ might reveal a cohort of cells containing gastric markers in deeper sections, although we think this unlikely. Future studies of this nature are clearly important, nevertheless. One alternative can be completely excluded however. Liu and Wright ${ }^{16}$ felt that it was distinctly possible that so-called gastric metaplasia was just an overgrowth of the epithelium of Brunner's gland ducts onto the villi. Our data show that this cannot be true as Brunner's gland duct cells contain no MUC5AC. In contrast, our observations that early patches of gastric metaplasia contain cells of rather indeterminate morphology between goblet and foveolar cells and that cells with foveolar morphology in early patches also package an immature form of intestinal MUC2 in their secretory granules, clearly argue that the immediate precursor is an intestinal mucin secreting cell. There is no reason to expect that these characteristics would arise in a unique gastric lineage.

It is important to emphasise that our evidence does not exclude reprogramming during the earliest stage of mucous secretingcell evolution at the stem cell level. Indeed, when metaplasia is widespread and advanced, affecting almost the entire duodenal mucosa, as it is in severe, chronic inflammatory lesions, almost all of the cells possess the gastric phenotype and very few goblet cells may be seen. In sections with extensive gastric metaplasia, such as those studied by Liu and Wright, ${ }^{16}$ cells with a gastric phenotype may arise in the crypt and stream upwards as a cohort toward the villus tip. Even in relatively 
mild metaplastic lesions the earliest goblet cells in some of the crypts may contain both gastric and intestinal mucins, suggesting that synthesis of gastric products can be induced at the stem cell level. The transformation to cells of a gastric phenotype appears to take place on the villous when lesions are focal however. Reprogramming appears to represent a dynamic process that is controlled at several levels of cellular maturation and is distinct from differentiation dependent lineage development. As inflammation increases the expression of gastric cells, it is quite likely that the process of changing a goblet cell to a foveolar cell phenotype is controlled by extracellular signals.

We thank Dr Herman Yaeger for his help with immunostaining of biopsy sections and for the generous provision of laboratory facilities. Dr Shaoul was a Canadian Cystic Fibrosis Foundation Research Fellow. He was also supported by grants from the American Physicians Fellowship for Medicine in Israel program, Janssen/Ortho Inc, and the Postgraduate Dyson Fellowship award from the University of Toronto.

1 Cheli R, Cornaggio M, Testino G, et al. Gastric metaplasia in normal (inflammation-free) duodenal mucosa. $\mathcal{F}$ Clin Gastroenterol 1994;18:240-1.

2 Shousha S, Parkins RA, Bull TB. Chronic duodenitis with gastric metaplasia: electron microscopic study including comparison with normal. Histopathology 1983;7:873-85.

3 Fitzgibbons PL, Dooley CP, Cohen H, et al. Prevalence of gastric metaplasia, inflammation, and Campylobacter pylori in the duodenum of members of a normal population. Am 7 Clin Pathol 1988;90:711-14.

4 Gormally SM, Kierce BM, Daly LE, et al. Gastric metaplasia and duodenal ulcer disease in children infected by Helicobacter pylori. Gut 1996;38:513-17.

5 Wyatt JI, Rathbone BJ, Sobala GM, et al. Gastric epithelium in the duodenum: its association with Helicobacter pylor and inflammation. Clin Pathol 1990;43:981-6.

6 Frierson HF, Caldwell SH, Marshall BJ. Duodenal bulb biopsy findings for patients with non-ulcer dyspepsia with
or without Campylobacter pylori gastritis. Mod Pathol 1990;3:271-6.

7 Moss S, Calam J. Helicobacter pylori and peptic ulcers: the present position. Gut 1992;33:289-92.

8 Shabib SM, Cutz E, Drumm B, et al. Association of gastric metaplasia and duodenitis with Helicobacter pylori infection in children. Am f Clin Pathol 1994;102:188-91.

9 Harris AW, Gummett PA, Walker MM, et al. Relation Harris AW, Gummett PA, Walker MM, et al. Relation between gastric acid output, Helicobacter pylori and gastric

10 Lechago J, Black C, Samloff IM. Immunofluorescence studies of gastric heterotopia of the small intestine in Crohn's disease. Gastroenterology 1976;70:429-32.

11 Yokoyama I, Kozuka S, Ito K, et al. Gastric gland metaplasia in the small and large intestine. Gut 1977;18:214-18.

12 Wright NA, Pike CM, Elia G. Ulceration induces a nove epidermal growth factor- secreting cell lineage in human gastrointestinal mucosa. Digestion 1990;46:125-33.

13 James AH. Gastric epithelium in the duodenum. Gut 1964; 5:285-94.
14 Patrick WJA, Denham D, Forrest APM. Mucous change in the human duodenum: a light and electron microscopic study and correlation with disease and gastric secretion. study and correlation

15 Wright NA, Pike C, Elia G. Induction of a novel epidermal growth factor-secreting cell lineage by mucosal ulceration in human gastrointestinal stem cells. Nature 1990;343:82-

16 Liu KC, Wright NA. The migration pathway of epithelial cells on human duodenal villi: The origin and fate of 'gastric metaplastic' cells in duodenal mucosa. Epithelial Cell Biol 1992;1:53-8.

17 Wright NA, Poulsom R, Stamp GWH, et al. Epidermal growth factor (EGF/URO) induces expression of regulagrowth factor (EGF/URO) induces expression of regulaPathol 1990;162:279-84.

18 Hanby AM, Poulsom R, Elia G, et al. The expression of the trefoil peptides pS2 and human spasmolytic polypeptide (hSP) in 'gastric metaplasia' of the proximal duodenum: implications for the nature of 'gastric metaplasia'. F Pathol 1993;169:355-60.

19 Rio M-C, Chenard M-P, Wolf C, et al. Induction of pS2 and $\mathrm{hSP}$ genes as markers of mucosal ulceration of the digestive tract. Gastroenterology 1991;100:375-9.

20 Wright NA. The ulcer-associated cell lineage (UACL); a newly recognized pathway of gastrointestinal differentiation of importance in the natural healing of peptic ulcer disease. In: Hunt RH, Tytgat GNJ, eds. Helicobacter pylori, disease. In: Hunt RH, Tytgat GNJ, eds. Helicobacter pylori, basic mechanisms to climical curc

21 Wright NA. Migration of the ductular elements of gut-associated glands gives clues to the histogenesis associated with responses to acid hypersecretory states. Yale $\mathcal{F}$ Biol Med 1996;69:147-53.

22 Shi S-R, Key M, Kalra KL. Antigen retrieval in formalinfixed, paraffin-embedded tissues: an enhancement method for immunohistochemical staining based on microwave oven heating of tissue sections. F Histochem Cytochem 1991; 39:741-8.

23 Lahoti C, Thorner P, Malkin D, et al. Immunochemical detection of $\mathrm{p} 53$ in Wilms tumors correlates with unfavorable outcome. Am f Pathol 1996;148:1577-89.

$24 \mathrm{McCool}$ DJ, Forstner JF, Forstner GG. Synthesis and secretion of mucin by the human colonic tumour cell line tion of mucin by the human coloni

25 Sotozono M, Okada Y, Sasagawa T, et al. Novel monoclonal antibody, SO-MUI, against human gastric MUC5AC apoantibody, SO-MUI, against human gastric MU
mucin. F Immunol Methods 1996;192:87-96.

26 Piggott NH, Henry JA, May FEB, et al. Antipeptide ntibodies against the pNR-2 oestrogen-regulated protein of human breast cancer cells and detection of pNR-2 expression in normal tissues by immunohistochemistry. $\mathcal{F}$ Pathol 1991;163:95-104.

27 Stemberger LA. Immunocytochemistry, 3 edn. New York: John Wiley and Sons, 1986.

28 Poulsom R, Chinery R, Sarraf C, et al. Trefoil peptide expression in intestinal adaptation and renewal. Scand $\mathcal{F}$ Gastroenterol 1992;27:17-28.

29 Wright NA, Poulsom R, Stamp G, et al. Trefoil peptide gene expression in gastrointestinal epithelial cells in inflammaexpression in gastrointestinal epithelial cells in inflam

30 Rubin DC, Swietlicki E, Gordon JI. Use of isografts to study proliferation and differentiation programs of mouse stomach epithelia. Am F Physiol 1994;267:G27-39.

31 Jeffery PK, Li D. Airway mucosa: secretory cells, mucus and mucin genes. Eur Respir f 1997;10:1655-62.

32 Ahnen DJ, Poulsom R, Stamp GWH, et al. The ulcerationassociated cell lineage (UACL) reiterates the Brunner's gland differentiation programme but acquires the proliferative organization of the gastric gland. F Pathol 1994;173: $317-26$. 